\title{
The prawns of the genus Macrobrachium (Crustacea, Decapoda, Palaemonidae) with commercial importance: a patentometric view
}

\author{
Olimpia Chong-Carrillo ${ }^{1}$, Ricardo Arencibia-Jorge ${ }^{2}$, Cristina Olimpia Chávez-Chong ${ }^{3}$ \\ Shehu L. Akintola ${ }^{4}$, Marcelo U. García-Guerrero ${ }^{5}$, Layla Michán-Aguirre ${ }^{6}$ \\ Héctor Nolasco-Soria ${ }^{7}$, Fabio Cupul-Magaña ${ }^{1}$ \& Fernando Vega-Villasante $^{1}$ \\ ${ }^{1}$ Laboratorio de Calidad de Agua y Acuicultura Experimental, Departamento de Biología \\ Centro de Investigaciones Costeras, Universidad de Guadalajara, Puerto Vallarta, Jalisco, México \\ ${ }^{2}$ Centro Nacional de Investigaciones Científicas, Playa La Habana, Cuba \\ ${ }^{3}$ Centro de Estudios de Matemática para las Ciencias Técnicas, Instituto Superior Politécnico \\ "José Antonio Echeverría", Cuba \\ ${ }^{4}$ Fisheries Department, Lagos State University, PMB 0001, LASU, Ojo, Lagos, Nigeria \\ ${ }^{5}$ Centro Interdisciplinario de Investigación para el Desarrollo Integral Regional-Instituto Politécnico Nacional \\ (CIIDIR-IPN) Unidad Oaxaca, México \\ ${ }^{6}$ Laboratorio de Cienciometría, Información e Informática Biológica, Facultad de Ciencias \\ UNAM. Coyoacán, Distrito Federal, México \\ ${ }^{7}$ Centro de Investigaciones Biológicas del Noroeste. La Paz, B.C.S. México \\ Corresponding author: Fernando Vega-Villasante (fernandovega.villasante@gmail.com)
}

\begin{abstract}
The scientific interest in the genus Macrobrachium was not only from a biological aspect, but also from economic aspect. This paper analyzed the patents identified in several databases using the keyword Macrobrachium. Patents were selected when a species of Macrobrachium was mentioned in main title. The total number of identified patents was 131, of which Chinese authors and institutions have produced more than $90 \%$. Topics addressed refer to culture technologies (41\%), nutrition and feeding (26\%), reproduction technologies $(19 \%)$ and pathological diagnosis and treatments (14\%). Patents are mainly directed for M. rosenbergii (71\%), M. nipponense (28\%) and M. superbum (1\%). Until now, it has not been attempts to generate patents to American continent species.
\end{abstract}

Keywords: Macrobrachium, prawn, patents, technology, innovation, aquaculture.

\section{Los camarones de río del género Macrobrachium (Crustacea, Decapoda, Palaemonidae) con importancia comercial: una visión patentométrica}

\begin{abstract}
RESUMEN. El interés científico por las especies del género Macrobrachium no ha sido solo desde el aspecto biológico, sino también económico. El presente trabajo analiza las patentes detectadas en diversas bases de datos utilizando la palabra clave "Macrobrachium". Se incluyeron las patentes que mencionaran en el título principal a alguna especie de Macrobrachium. Se encontraron 131 patentes, de las cuales instituciones y autores chinos han producido más del 90\%. Las temáticas abordadas se refieren a las tecnologías de cultivo (41\%), nutrición y alimentación (26\%), tecnologías de reproducción (19\%), y diagnóstico patológico y tratamientos (14\%). Las especies a las que son dirigidas las patentes son $M$. rosenbergii $(71 \%)$, M. nipponense $(28 \%)$ y M. superbum $(1 \%)$. No se ha publicado ninguna patente para especies del continente americano.
\end{abstract}

Palabras clave: Macrobrachium, camarón de río, patentes, tecnología, innovación, acuicultura.

\section{INTRODUCTION}

Among the infraorden Caridea, the family Palaemonidae includes 125 genera with 239 species (De Grave et al., 2009). Macrobrachium (Bate, 1868) constitutes the most diverse genus among the palaemonids, distributed in tropical and subtropical streams and rivers around the world (Bauer, 2011). These shrimps are co-

Corresponding editor: Erich Rudolph 
lloquially called prawns, acamayas, cauque, langostino or shrimp, depending on the region in which they are found (García-Guerrero et al., 2013). The scientific interest in the genus Macrobrachium is not limited to a biological point of view, but also includes social and economic aspects. Many of these species are subject of traditional fisheries and culture (García-Guerrero et al., 2013). According to New (2009), production of prawns reaches hundreds of thousands of tons per year, most of which are $M$. rosenbergii (De Man, 1878), which is originally from Asia. This species known as "Malaysian shrimp" or "giant river prawn" has been the most studied one, and its farming production technology has been exported to many countries outside their original distribution area.

Since 1980, after the first meeting in Thailand on the culture of $M$. rosenbergii, there has been increased scientific research directed towards establishing optimal conditions for controlled production of this species, as well as native Macrobrachium species of economic importance (New \& Nair, 2012).

Chong-Carrillo et al. (2015) showed development on the research of this important genus of crustaceans, highlighting where efforts of research groups and countries are going, and what knowledge gaps remain unfulfilled. However, information addressing the phenomenon of published science transfer towards generating technologies or (protected as patents) innovations aimed at improving Macrobrachium culture (which is the final goal in the development of technology in aquaculture) is yet to be addressed. According to Schmoch (1993), an obvious method to track the knowledge transfer from science to technology is patent analysis. In this sense, Plaza \& Albert-Martínez (2009) noted that the indicators derived from these studies are effective ways to assess the impact of scientific research on technological development.

This paper aimed to contribute to the development of Macrobrachium genus research, through scientometric study of patents granted and registered in the main international patent databases in the past three decades and the present, in order to establish where the technology generation efforts are directed, and if there is a direct relationship between patents and published science.

\section{MATERIALS AND METHODS}

The study is based on the collection of patents from the following databases: Patentscope (®) of the World Intellectual Property Organization (WIPO) and ISI (Institute for Science Information®). Patents were selected when a species of Macrobrachium was mentioned in the main title. From the information obtained, a database with EndNote software was created for handling and processing the data. For the standardization of data card patent were made containing the following information: Title of the patent, main inventor (according to WIPO or ISI), date of publication, patent number, assignment and summary. Based on the records, the classification of patents held four themes: i) culture, ii) nutrition/ feeding, iii) pathology diagnosis/treatments, and iv) reproduction. Within each theme, patents were classified in turn into subtopics to highlight areas of innovation with greater productivity. The resulting data were transferred to spreadsheets for handling and processing of graphics.

\section{RESULTS}

Since the early ' 70 s to 2015,131 patents were detected using the title keyword Macrobrachium.

\section{Countries}

Only five countries worldwide have developed patents for the prawns of the Macrobrachium genus. The results showed that China leads the production of patents for Macrobrachium with 123 patents (over 90\% of patents record) in all subject areas, Israel (2\%), Russia (2\%), Malaysia (1\%), and the United States of America (1\%) distantly follow it (Fig. 1a).

Out of the ten most productive institutions (those that have generated at least three patents), nine are Chinese. The maximum number of patents produced by a single institution is 23 and corresponds to China. The institutions included in the result shown in Figure 1b, generated 66 patents, corresponding to $50 \%$ of the total number of registered patents. This phenomenon is also reflected in the number of more productive authors (those with at least three patents). Eight Chinese technologists produced 37 patents (alone or in collaboration), almost $30 \%$ of 123 for that country. The most productive are those that have produced 3 to 7 patents. Among the most productive authors was just one, from Israel, who generated (alone or in collaboration) three patents.

\section{Relationship between published science and patents generation}

Number of patents granted and the number of scientific articles published on the subject Macrobrachium have a dissimilar trend in the growth of both over time. Only a few patents were generated from the 80 s to the middle of the first decade of XXI century. The production of 

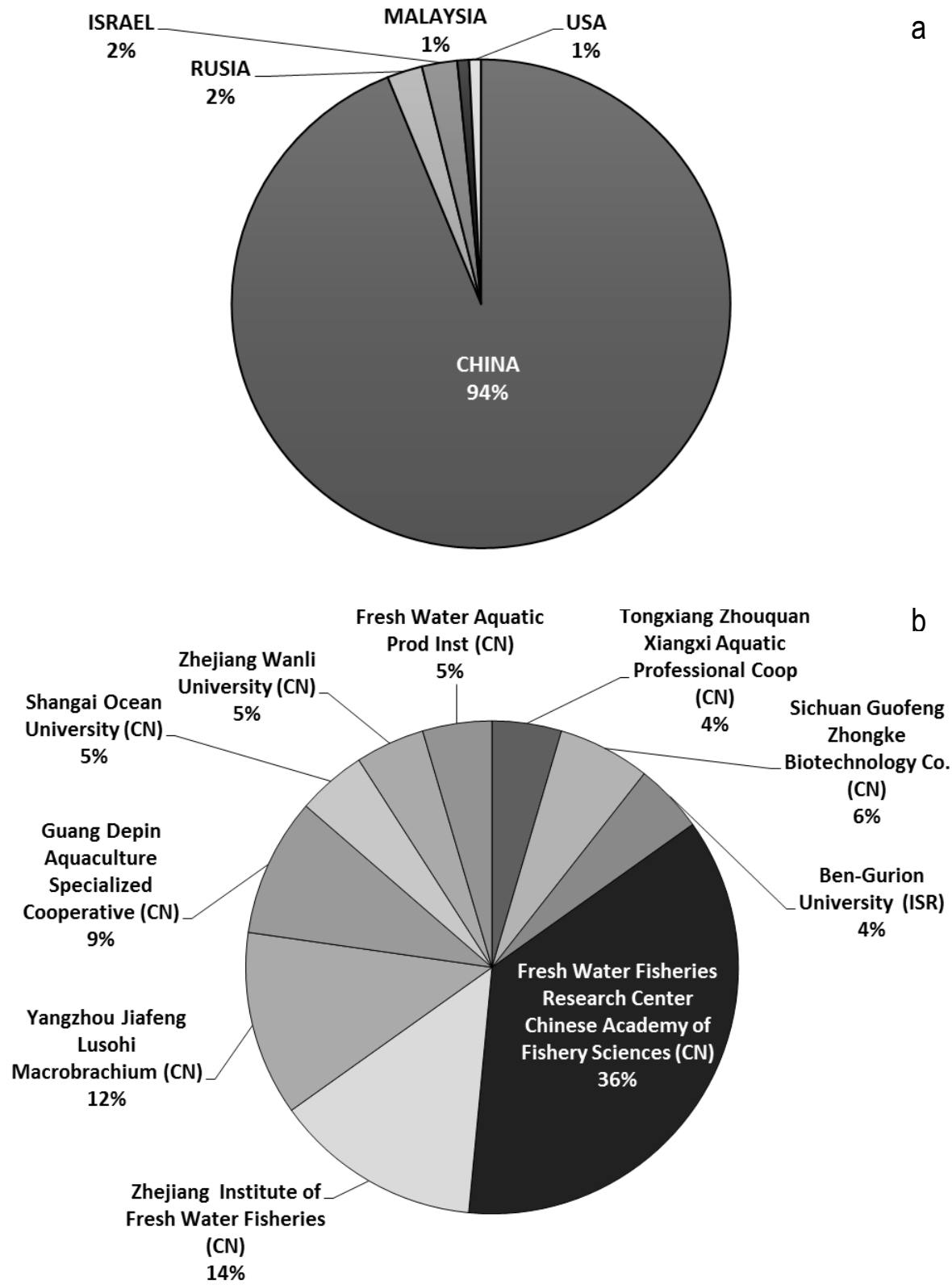

Figure 1. a) Main countries and institutions, b) producing patents on Macrobrachium at a global scale. CN: China, ISR: Israel.

specific patents, for prawns of the Macrobrachium genus, begins to increase in 2008, an increase sustained to date. In the case of scientific manuscripts, production began moderately from the ' 80 s to early XXI century, showing, in the following years, a significant increase, however has suffered significant declines (Fig. 2). Between 2008 to 2011 and 2014 there were abrupt decreases in the number of published articles, and a dramatic increase of patents generated particularly in 2011 (the same year of the most pronounced fall of publications).

\section{Species}

The technologies developed directly for this genus of crustacean totaled $71 \%$ for $M$. rosenbergii, $28 \%$ for $M$. nipponense (De Haan, 1849), and $1 \%$ for M. superbum (Heller, 1862).

\section{Thematic area}

The theme culture, has the highest number of patents (41\%), followed by nutrition/feeding (26\%). Both subjects far exceeded $50 \%$ of total production, while the other issues, pathology diagnosis/treatments and re- 


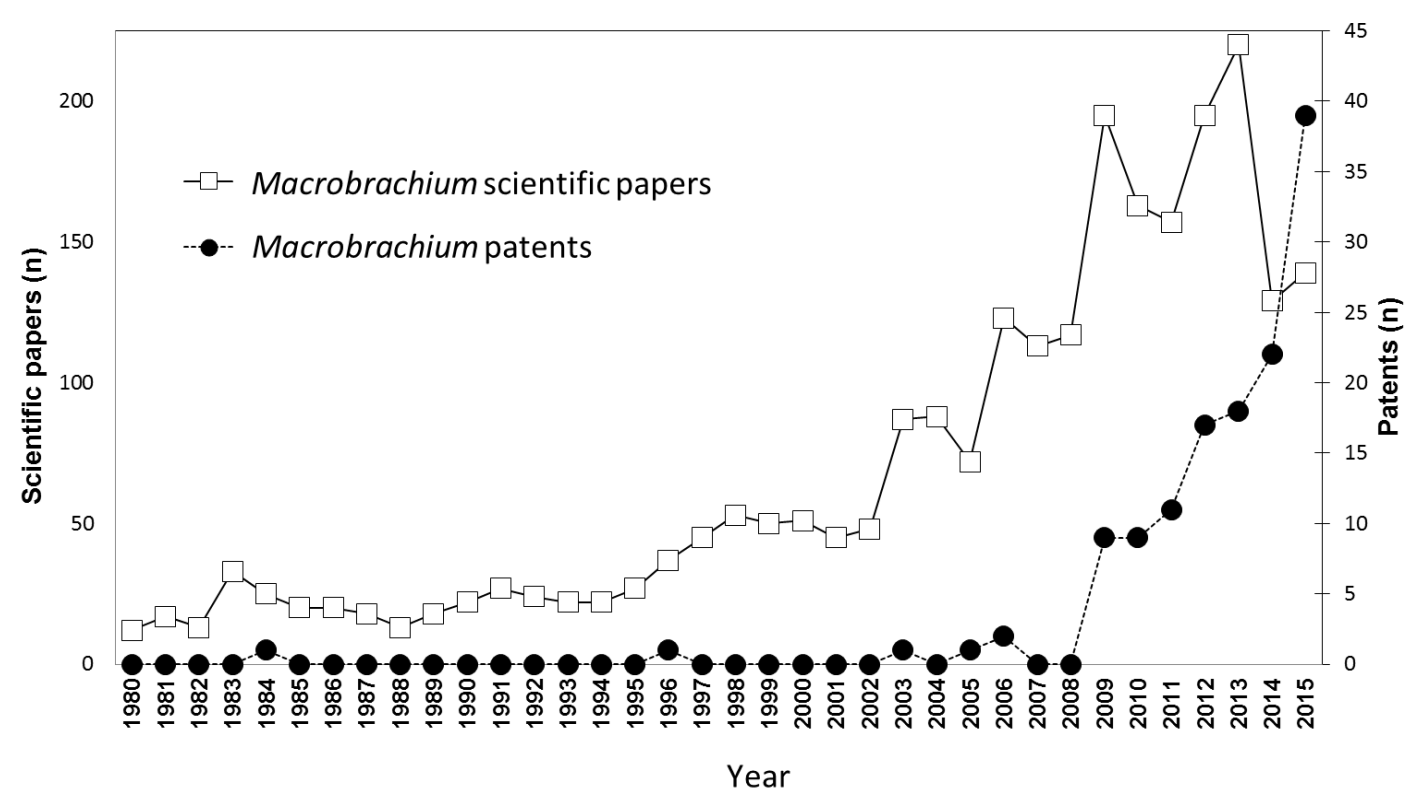

Figure 2. Number of granted patents and scientific papers published from 1980 to 2015, on Macrobrachium.

production have remained at a lower level (Fig. 3). Only China has generated technologies on all main areas.

\section{Subthemes}

The results show for the case of the culture theme, that the subtheme innovation of culture technologies is the one most patents generated (44\%). This included changes in traditional farming technologies through management of water and organisms in culture as well as harvest time, among other topics aimed at improving culture yields. The subtheme equipment (24\%) included designs of filtration, recirculation, and recycling systems, as well as innovative devices. The techniques that deal with two species-polyculture management have also been subject of protection (20\%) as well as those aimed at innovating monosex culture (12\%) (Fig. 4a).

For the nutrition thematic, most patents are directed to the protection of whole food formulations, for the development of organisms in culture (49\%) and special dietary formulations that meet a specific function in the metabolism of organisms (27\%). The protection of methodologies for the production of biofilms (biobed) also showed significant progress (15\%), and it is the emerging subtopic within this knowledge area. Attention has been devoted to additives, designed to increase the nutritional quality of feeds $(6 \%)$, and formulations of larvae diets (3\%) which are essential for the efficient start of the production process of prawn species (Fig. 4b).

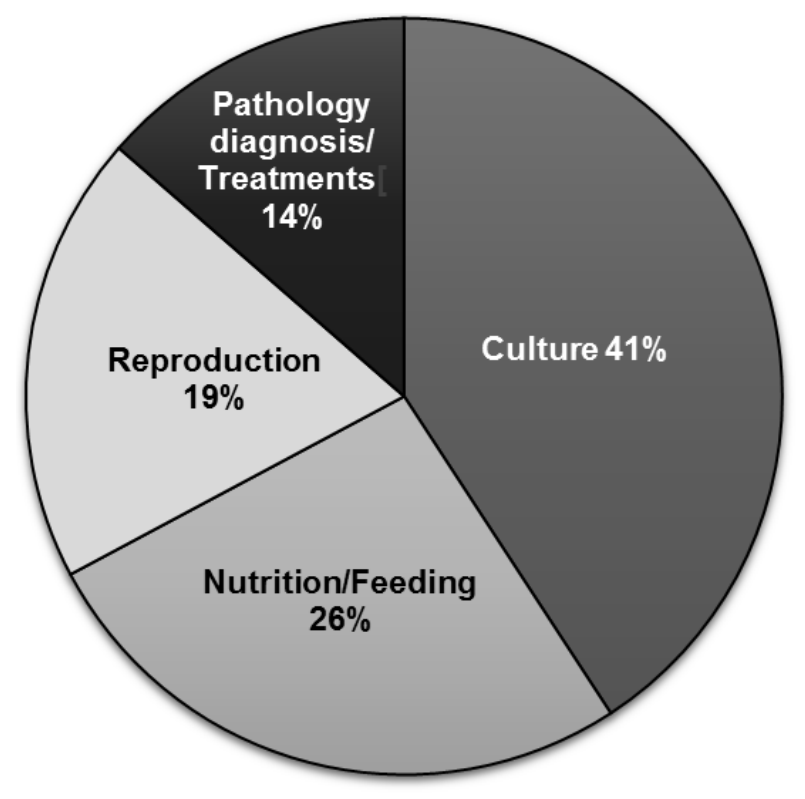

Figure 3. Main themes on Macrobrachium patents.

In the reproduction main theme, two sub-themes were included and involving the protection of breeding techniques $(75 \%)$, in which traditional hybridization methods were established and the reproduction management through molecular tools. Patents, which protect the optimum management of mature organisms, that ensures a higher reproductive performance $(25 \%)$ (Fig. $4 c)$ have also main attention.

In pathology, subtopic diagnosis is the most prevalent $(65 \%)$. In this, traditional test using immunelogical techniques or molecular biology were included. All directed at the identification of etiologic agents of 

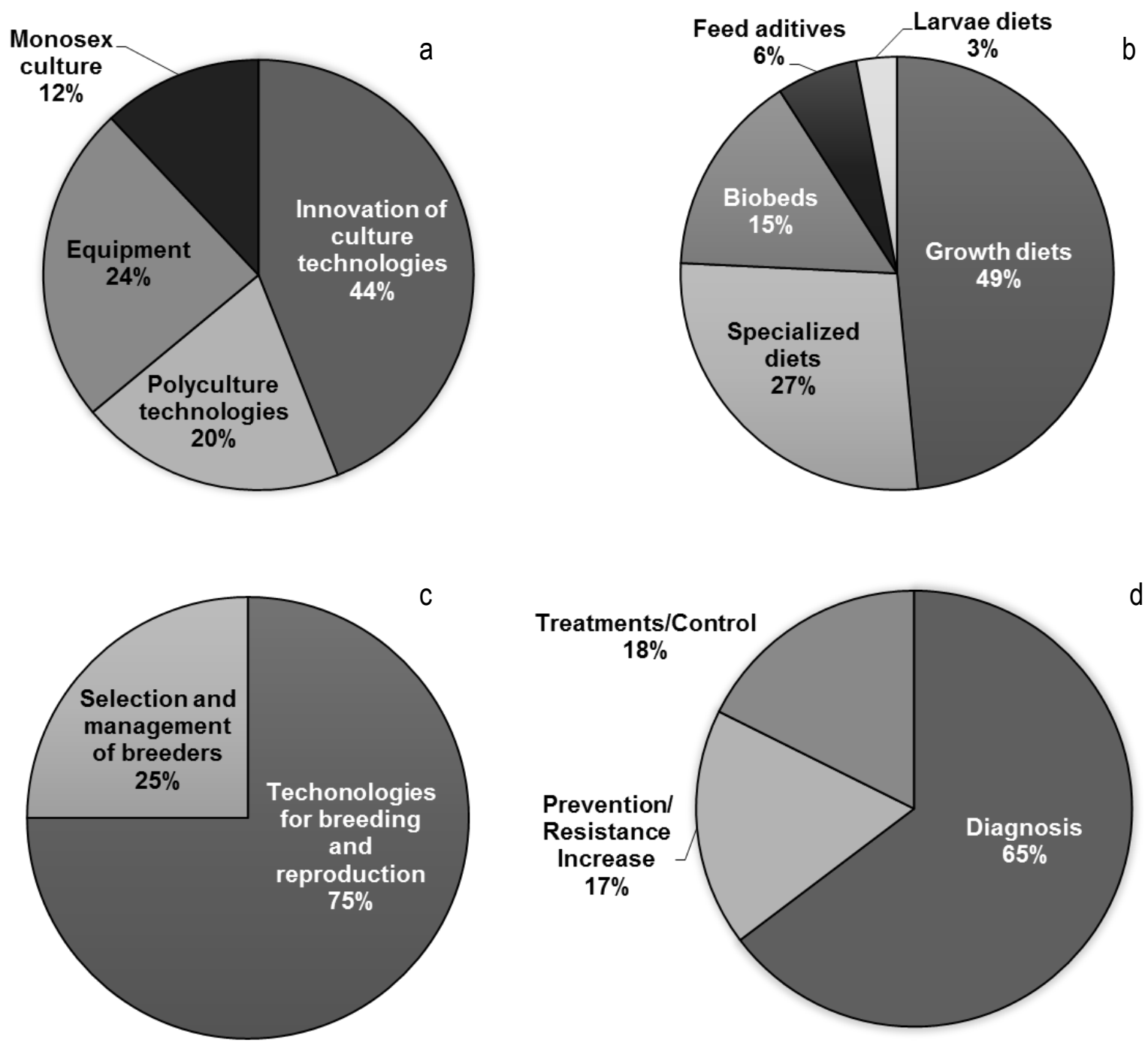

Figure 4. a) Percentage of patents on Macrobrachium according the subthemes within the main themes addressed. a) Culture, b) nutrition/feeding, c) reproduction, d) pathology diagnosis/treatments.

organisms in culture. In the subtopic prevention/ increasing resistance, technologies developed through molecular biology and food additives, designed to prevent specific infections through stimulation of defense systems $(17 \%)$ were included. In the subtopic treatment/control, methodologies or products developed for the treatment of established diseases and its control (18\%) were included (Fig. 4d).

\section{DISCUSSION}

Only China has generated technologies in all main areas. The rapid development in recent decades, molecular biology techniques and genomics have also impacted the development of patents directed to practically all culture areas related to crustaceans with commercial importance, including the genus Macro- brachium. In our first classification in this study, patents including such techniques were selected along the traditional genetics (crosses and desirable heritable characteristics) to form a separate thematic section. However, since them all address culture, pathology, and reproduction technologies, we finally included them within these main themes. The thematic areas: culture and nutrition/feeding covered by patents matched two of the areas mentioned by Chong-Carrillo et al. (2015) as the most productive in terms of scientific publications in academic journals, a phenomenon repeated in the generation of patents.

However, it should be noted that the generation of patents on reproduction and pathology diagnosis/ treatment exceeded proportionately the production of manuscripts on these areas. This was possible because greater research effort is aimed at generating techno- 
logies that can be protected and commercialized. The generation of patents on various topics, rose dramatically from the later 2000s and follows a sustained increase to date.

When the relationship between the number of patents granted and the number of scientific articles published on the subject Macrobrachium was analyzed, it was found a dissimilar behavior in its development. At several times in the timeline, the production of scientific papers presented serious increases and decreases (Fig. 3), a phenomenon that was commented by Chong-Carrillo et al. (2015) as the possible consequence of the global economic crisis that hit all sectors of the global development, including science (Chinn, 2010). Contradictorily, a dramatic increase of patents generated particularly in 2008 (the same year of the first pronounced fall of publications). The same phenomenon, and certainly more accentuated, observed in 2014, in which the production of scientific manuscripts drops abruptly, while production patent remains on the rise. It is probable that this event can be explained as part of the global crisis, when scientific publication in the area was unattractive compared to generating technologies for potential commercial applications (and thus the possibility of being sold) was more financially rewarding for scientists and technologists. It is noteworthy that sustained increment of patent production has not been a cumulative global effect, but because of just one country, China. This is undoubtedly a clear demonstration of the interest of the Asian giant to address the technological production in virtually all areas of aquaculture, including Macrobrachium culture. At present times, China continues to dominate overall aquaculture production (Van Dam et al., 2015). Its higher technology production on this area could be the explanation of this. It is also necessary to note the abysmally poor patents, in the field of study on the genus Macrobrachium by Latin American and African countries. In the case of Latin America, Brazil, which leads in the production of published scientific research on the genus Macrobrachium, at continental level (Chong-Carrillo et al., 2015), and the generation of patents on many of the thematic subspecialties of the International Patent Classification (Díaz-Pérez et al., 2010), the production of patents directed to Macrobrachium is zero. Because of its contributions with native species, according to Chong-Carrillo et al. (2015), Latin America, as a whole, is the geo-economic region with the highest productivity as demonstrated in published science on the genus Macrobrachium. However, this has not resulted in protection technologies through the generation of patents. This same phenomenon is observed with India leading the scientific production published in the world (mainly working with $M$. rosenbergii) (Chong-Carrillo et al., 2015), but has not a single patent registered.

According to Guzmán-Sánchez (1999), where there is little scientific research there is no state-oriented support system, therefore lacked adequate technological protection laws and patent collections do not exist or are deficient. However, the above should not be applied to countries such as India and Brazil, as its scientific production (combined) for the Macrobrachium genus, represents more than $35 \%$ of the world total, but do not have a proportional number of patents. In this sense the comparison with China is necessary because even though this country is below the aforementioned India and Brazil, with respect to scientific production on Macrobrachium published in scientific journals $(9.4 \%$ of world total) (ChongCarrillo et al., 2015), dramatically surpasses the above mentioned countries.

This phenomenon may be the product of different but not mutually exclusive factors: i) governments have failed to stimulate the generation of technologies for the culture of native species, including Macrobrachium species, ii) researchers in the field have no interest in developing patents but scientific publications instead, as patents do not result in a direct or short-term benefit, iii) there is an idiosyncrasy from researchers to their peers, based on sharing, in a solidary manner, technological advances in the culture of native species (W.C. Valenti, com. pers.).

Although the study of global patents is a tool to assess the generation of knowledge in a determined area or topic, it does not necessarily reflect the scientific and technological capacity of a country. Patent production certainly carries an interest for the protection of technologies with potential to be commercialized, while science and technology publication in journals of varying public access (open access or subscription) showed a liberal sense for transfer of results derived from a research process. Certainly, this attitude of sharing new knowledge to a global community is what has evolved in the case of science at current levels. The non-generation of patents, on river shrimp culture technologies in Latin America, does not suggest the inability of scientists and technologists but a lack of interest of the same, or of the institutions of science and technology to stimulate protection by patents, despite the great development in scientific research on the subject-genus Macrobrachium by some countries in this region.

The case of China remains a peculiar scenario of aquaculture worldwide, as it is not only a leading producer with amounts that dwarf those of other countries, but it is already a reference also in generating technologies in virtually all areas of Macrobrachium 
culture. Although M. nipponenseis is not subjected to global culture, as $M$. rosenbergii, and the amount of published science is not comparable, Chinese technologists have produced, in a short time, a large number of patents for $M$. nipponense. If this trend continues, it is likely that culture technologies for $M$. nipponense will exceed those of $M$. rosenbergii in the near future.

The China's experience in patenting should be studied, and if necessary, adapted especially for emerging economies. The current technological and economic power of this Asian nation has been a project designed for that purpose and not random. As Faust (1990) mentioned that, the early detection of changes in technological development, both in terms of direction and intensity, was gaining importance in making political and economic decisions. The Asian giant is a prime example of this. This type of documents, understood as a science-based product, has the essential information for stable technological development. Also constitutes a fundamental reference for technologists and researchers to create technical solutions that modify, facilitate, and enforce the tools to ensure optimal development of productive processes, in this case the culture of Macrobrachium with commercial interest.

\section{CONCLUSSIONS}

Just 131 patents were detected since the early ' 70 s to the 2015, using the keyword Macrobrachium. Only six countries worldwide have developed patents for the river shrimp of the Macrobrachium genus. Only China has generated technologies on all main areas. The results showed that China leads the production of patents for Macrobrachium with 123 patents in all subject areas. Specifically, patents technologies were developed directly only for $M$. rosenbergii and $M$. nipponense. The theme culture, has the highest number of patents followed by nutrition/feeding with both recording more than half of the patents. Macrobrachium research in Latin America has not resulted in protected technologies. China's experience in patents should be adapted especially for emerging economies. Patents are essential documents for full understanding the state of the art of a determined scientific area.

\section{ACKNOWLEDGEMENTS}

We thank the National Council for Science and Technology of Mexico for the doctoral scholarship granted to the first author of this paper. Special thanks for the anonymous reviewers of our manuscript.

\section{REFERENCES}

Bauer, R.Tiven. 2011. Amphidromy and migrations of freshwater shrimps. I. Costs, benefits, evolutionary origins, and an unusual case of amphidromy. In: A. Asakura (ed.). New frontiers in crustacean biology. Proceedings of the Crustacean Society Summer Meeting. Tokyo, 20-24 September 2009, Brill, Leiden, pp. 145-156.

Chong-Carrillo, O., F. Vega-Villasante, R. ArencibiaJorge, S.L. Akintola, L. Michán-Aguirre \& F.G. Cupul-Magaña. 2015. The research on the river shrimps of the genus Macrobrachium (Bate, 1868) with known or potential economic importance: strengths and weaknesses shown through scientometrics. Lat. Am. J. Aquat. Res., 43(4): 684-690.

Chinn, L.W. 2010. The global state of science funding. ASBMB today, May: 18-19. [http://http://www. asbmb.org/asbmbtoday/asbmbtoday_article.aspx?id= 7350]. Reviewed: 3 March 2016.

De Grave, S., N.D. Pentcheff, S.T. Ahyong, T.Y. Chan, K.A. Crandall, P.C. Dworschak, D. Felder, R.M. Feldmann, C.H.J.M. Fransen, L.Y.D. Goulding, R. Lemaitre, M.E.Y. Low, J.W. Martin, P.K.L. Ng, C.E. Schweitzer, S.H. Tan, D. Tshudy \& R. Wetzer. 2009. A classification of living and fossil genera of decapods crustaceans. Raffles Bull. Zool., Suppl. 21: 1-109.

Díaz-Pérez, M., S. Rivero-Amador \& F. Moya-Anegón. 2010. Producción tecnológica latinoamericana con mayor visibilidad internacional: 1996-2007. Un estudio de caso: Brasil. Rev. Esp. Doc. Cient., 33: 34-62.

Faust, K. 1990. Early identification of technological advances on the basis of patent data. Scientometrics, 19: 473-480.

García-Guerrero, M.U., F. Becerril-Morales, F. VegaVillasante \& L.D. Espinosa. 2013. Los langostinos del género Macrobrachium con importancia económica y pesquera en América Latina: conocimiento actual, rol ecológico y conservación. Lat. Am. J. Aquat. Res., 41(4): 651-675.

Guzmán-Sánchez, M.V. 1999. Patentometría herramienta para el análisis de oportunidades tecnológicas. Universidad de La Habana, La Habana, [bvv.finlay.edu. cu/download.php?url=documentos/119566413228.pd f]. Reviewed: 3 March 2016.

New, M. 2009. History and global status of freshwater prawn farming. In: M.B. New, W.C. Valenti, J.H. Tidwell, L.R. D'Abramo \& M.N. Kutty (eds.). Freshwater prawns: biology and farming. Wiley Blackwell, New York, pp. 1-11.

New, M. \& M. Nair. 2012. Global scale of freshwater prawn farming. Aquacult. Res., 43: 960-969. 
Plaza, L.M. \& A. Albert-Martínez. 2009. Análisis de la producción científica española citada en patentes biotecnológicas en EE.UU. Rev. Esp. Doc. Cient., 27: 212-220.

Schmoch, U. 1993. Tracing de knowledge transfer from science to technology as reflected in patent indicators. Scientometrics, 26: 193-211.

Received: 24 December 2015; Accepted: 18 May 2016
Van Dam, A.A., W.C. Valenti, W. Zhang, B. Austin, J.A.H. Benzie, B.A. Costa-Pierce, A.P. Farrell, D.M. Gatlin, G. Hulata \& D.C. Little. 2015. Introducing: aquaculture reports. Aquacult. Rep., 1: A1-A2. 